\title{
Después de Genealogías feministas. Estrategias feministas de intervención en los museos y tareas pendientes
}

\author{
Patricia MAYAYO ${ }^{1}$ \\ Universidad Autónoma de Madrid \\ patricia.mayayo@uam.es
}

Recibido: 25.09 .2013

Aceptado: 20.11.2013

\section{RESUMEN}

Partiendo de la experiencia de la reciente exposición Genealogías feministas en el arte español, 1960-2010, este artículo se propone reflexionar sobre el alcance, pero también sobre las limitaciones, de lo que podríamos denominar, simplificando, como el modelo de "exposición temporal feminista". ¿Hasta qué punto hemos conseguido, con este tipo de muestras, cambiar o, al menos, desestabilizar el canon? ¿Han ido incorporándose parte de estas investigaciones a los discursos de los principales museos y a la literatura académica sobre el arte español? ¿En qué medida han contribuido estas exposiciones a ese replanteamiento crítico y autorreflexivo de nuestras propias herramientas metodológicas que debería ser inherente a todo conocimiento feminista? ¿Cómo se han ido reformulando las categorías "mujer artista" y "práctica artística feminista" y cómo se ha ido articulando la relación (o la tensión dialéctica) entre ambas? ¿Qué tareas, en definitiva, siguen pendientes?

Palabras clave: Feminismo y arte contemporáneo en España, Historia de las mujeres artistas españolas, Historiografía feminista, Estrategias feministas de intervención en museos y centros de arte.

\section{After Genealogías Feministas.}

Feminist strategies for intervention in museums and tasks to be done.

\begin{abstract}
Taking as a point of departure the case of the recent exhibition Feminist Genealogies in Spanish Art, 19602010, this paper discusses the role, but also the shortages, of feminist temporary exhibitions. To what extent have this kind of exhibitions been successful in changing or, at least, destabilizing the canon of contemporary Spanish art? Have they influenced the discourse of main art museums and scholarly research? Have they helped us to reconsider our own methods and points of view? How have the categories "women artist" and "feminist art" been redefined? And finally, what is still to be done?
\end{abstract}

Key words: Contemporary art and feminism in Spain, Spanish women artists, Feminist art history, feminist strategies in museums and art galleries

${ }^{1}$ Este artículo ha sido escrito gracias al trabajo realizado dentro del proyecto de investigación “¿Corpus auctoris? Análisis teórico-práctico de los procesos de autorización de la obra artístico-literaria como materialización de la figura autorial" (FFI2012-33379). 
En junio de 2012 se inauguraba en el Museo de Arte Contemporáneo de Castilla y León (MUSAC) la exposición Genealogías feministas en el arte español, 1960-2010, que tuve el privilegio de comisariar junto a Juan Vicente Aliaga. Nuestro trabajo era deudor de toda una serie de muestras -desde 100\% (1993), considerada habitualmente como la primera exposición de arte feminista de nuestro país, hasta En todas partes. Políticas de la diversidad sexual en el arte (2010), pasando por Territorios indefinidos (1995), Cómo nos vemos. Imágenes y arquetipos femeninos (1997), Transgenéric@s (1998), Zona F (2000) o El bello género (2002), por citar solo una cuantas- que desde principios de los años noventa habían ido introduciendo los discursos feministas y queer en el mundo artístico español. Muchas de estas propuestas, sin embargo, se centraban en un periodo, contexto geográfico o artistas muy concretas y parecía necesario, por lo tanto, emprender una investigación más amplia, que intentase dar una visión de conjunto de las relaciones entre el arte y las políticas feministas en el Estado español desde el tardofranquismo.

Nos interesaba abarcar un arco temporal dilatado (desde los primeros años sesenta del siglo pasado hasta los inicios del XXI, marcados por la irrupción de un nuevo conjunto de prácticas artísticas y activistas conocidas con el nombre de "transfeminismos") para contrarrestar la imagen tópica de que los discursos feministas no llegaron al arte español sino de forma tardía, en la década de los noventa, como producto de la importación rezagada de "modas" anglosajonas. La exposición Genealogías feministas subrayaba las peculiaridades del caso español, que no puede ser analizado extrapolando, sin más, modelos foráneos. En nuestra opinión, desde los años sesenta es posible identificar en la obra de algunas artistas españolas una indagación sobre las injusticias de la sociedad (hetero)patriarcal que cabría describir como protofeminista y que a lo largo de la década siguiente, con la consolidación del movimiento feminista y el final del franquismo, se volverá abiertamente política. Sin embargo, esta veta antipatriarcal ha sido ignorada en general por la historia oficial (que se ha limitado a ver en estos trabajos un deseo de crítica "social") y también, en gran medida, por ese conjunto de exposiciones feministas a las que aludíamos más arriba, centradas -salvo excepciones- en la obra de artistas que iniciaron su carrera a partir de los noventa.

Nuestra intención no ha sido, en cualquier caso, trazar una historia cerrada y definitiva, sino proponer una lectura que pueda ser cuestionada, discutida y enriquecida en el futuro. No quiero volver a analizar aquí los contenidos y estructura de la muestra, que han sido estudiados en detalle en el catálogo editado para la ocasión (Aliaga y Mayayo, 2012). Por el contrario, me gustaría más bien reflexionar sobre lo que no hemos hecho: dicho de otro modo, partiendo de la experiencia concreta de Genealogías feministas, quisiera meditar -aunque sea de forma somera e incompleta- sobre el alcance, pero también sobre las limitaciones, de lo que podríamos denominar, simplificando, como el modelo de "exposición temporal 
feminista". ¿Hasta qué punto hemos conseguido, con este tipo de muestras, cambiar o, al menos, desestabilizar el canon? ¿Han ido incorporándose parte de estas investigaciones a los discursos de los principales museos y a la literatura académica sobre el arte español? ¿En qué medida han contribuido estas exposiciones a ese replanteamiento crítico y autorreflexivo de nuestras propias herramientas metodológicas que debería ser inherente a todo conocimiento feminista? ¿Cómo se han ido reformulando las categorías "mujer artista" y "práctica artística feminista" y cómo se ha ido articulando la relación (o la tensión dialéctica) entre ambas? ¿Qué tareas, en definitiva, siguen pendientes?

\section{LA (SEMPITERNA) RESISTENCIA DEL CENTRO}

Una primera lección que podríamos extraer de la experiencia de Genealogías feministas es que, veinte años después de la celebración de $100 \%$, sigue resultando muy difícil vencer la resistencia de las instituciones artísticas "de cabecera" a incorporar el legado feminista. Como ha observado Olga Fernández López, la gran mayoría de las exposiciones feministas de las últimas décadas han tenido lugar en espacios alejados de los centros tradicionales: en particular, resulta llamativa la concentración de muestras en Andalucía, Comunidad Valenciana, País Vasco y Galicia frente a Madrid y Cataluña. Más aún, la mayor parte no se han producido en los nuevos museos de arte contemporáneo, sino en lo que la autora describe como el "el circuito adicional": un conjunto diseminado de salas municipales y provinciales, menos remisas a abrirse a los discursos de género que las instituciones de ámbito estatal o autonómico (Fernández López, 2012: 107-108).

El caso de Genealogías feministas parece confirmar esta tendencia. En primer lugar, hay que decir que, a pesar de múltiples esfuerzos y gestiones, no hemos conseguido que la exposición itinerase a ninguna otra institución española. Pensábamos que el trabajo realizado (dos años de investigación y más de 150 obras reunidas) merecía ser disfrutado por otros públicos y en otros lugares; para nuestra sorpresa, nos hemos encontrado con reiteradas excusas y negativas. Podría argüirse que las razones de este rechazo estriban en la falta de interés o calidad de la muestra, aunque precisamente la tradición feminista ha contribuido más que ninguna a desvelar las trampas ideológicas que se esconden tras "los juicios de calidad". En cualquier caso, el tejido de instituciones en España es lo suficientemente amplio y diverso como para que esta propuesta pueda encajar, como lo hacen tantas otras, en la línea y programación de algún centro. También podría argumentarse la difícil situación económica que atraviesan muchos museos, pero es justamente en momentos de crisis cuando las redes de colaboración entre centros deberían hacerse más sólidas y cuando éstos deberían sentirse más proclives a aprovechar el trabajo y las inversiones ya realizados por otros. Me temo que nos encontramos ante otra prueba (una más) de la 
hostilidad de las instituciones españolas (especialmente de aquellas que siguen teniendo la misión de representar "el espíritu nacional", ya sea el Museo del Prado, el Museo Nacional Centro de Arte Reina Sofía o el Museo Nacional de Arte de Cataluña) a las perspectivas feministas y queer.

Si pensamos en el centro que ha acogido la muestra, el MUSAC, no solo se trata, siguiendo el análisis de Fernández López, de un museo periférico, sino de una institución que ha mostrado desde su origen un claro interés por el universo feminista y que ha sido incluso galardonada por la Asociación Mujeres en la Artes Visuales (MAV) por su compromiso con las políticas de igualdad. Una vez más, parece que nos viésemos abocadas a "predicar entre conversas" y que veinte años de "exposiciones temporales feministas" hubiesen logrado hacer escasa mella en el núcleo duro del discurso oficial.

Puede que haya llegado la hora, entonces, de revisar nuestras estrategias. ¿No deberíamos, quizá, desviar un poco la atención de las muestras temporales e intentar intervenir con más ahínco en el diseño de las colecciones permanentes? En efecto, a pesar de los réditos en términos de público y "espectáculo" que las temporales confieren a los museos, es en sus colecciones permanentes donde se consolida el discurso historiográfico. Bien es verdad que hoy en día la distinción entre ambas categorías, colección permanente y exposición temporal, es cada vez más difusa, toda vez que la presentación de la colecciones ya no se considera inamovible y suele ser revisada con frecuencia y que muchas veces las exposiciones temporales sirven de laboratorio de experimentación para proponer nuevos modelos historiográficos que luego se trasladan a la colección. No obstante, pensemos que si las instituciones centrales se muestran reacias a albergar exposiciones feministas, lo son todavía más a que dichas exposiciones, si llegan a celebrarse, "contaminen" la organización de la colección.r

Presionar a los responsables de los museos, como lo ha hecho MAV, publicando informes en los que se destaca el bajo porcentaje de mujeres artistas presentes en sus colecciones, exigiendo que se inventaríe y muestre al público la obra de mujeres contenida en los almacenes o realizando acciones de denuncia en fechas señaladas puede ser, sin duda, una estrategia fructífera ${ }^{2}$. También lo es el proponer-como hizo en su día el Instituto de Investigaciones Feministas de la Universidad Complutenserecorridos educativos por los museos que incorporen la perspectiva feminista, aunque se corre el riesgo de que estos itinerarios se consideren como un mero añadido que se "superpone" a la colección sin incidir en su estructura o contenidos (es lo que ha ocurrido, de hecho, con el recorrido a través de la Colección 1, "Feminismo. Una

\footnotetext{
${ }^{2}$ http://www.mav.org.es/
} 
mirada feminista sobre las vanguardias", que oferta el MNCARS, a instancias del Instituto, entre sus actividades educativas ${ }^{3}$ ).

La presión ha de ejercerse también en otras direcciones. Pienso que hasta ahora hemos hecho demasiado hincapié en los contenidos y actividades de los museos y muy poco en sus estructuras. Hoy en día la mayor parte de las instituciones artísticas siguen sometidas a una organización vertical, jerarquías estrictas y un excesivo protagonismo de la figura del director o directora (sobre todo del primero, ya que según el Informe $M A V n^{\circ} 10$, de enero de 2013, el 78\% del total del total de directores de centros españoles son hombres). En los últimos años, se han hecho muchos esfuerzos en exigir el cumplimiento de la Ley orgánica de igualdad entre hombres y mujeres 3/2007, que en su artículo 26 insta a las instituciones culturales de titularidad pública a promover acciones positivas en favor de la igualdad y a garantizar la paridad en sus órganos de consulta y decisión. Puesto que la ley sigue en gran medida sin cumplirse, debemos insistir machaconamente en ese objetivo.

Al mismo tiempo, sería necesario también conseguir que los centros públicos incorporasen en sus esquemas de funcionamiento modos de trabajo herederos de la tradición feminista: horizontalidad, co-participación, incorporación de los afectos y subjetividades como modo de conocimiento, des-jerarquización y trabajo colaborativo, politización de los procesos de trabajo... Quizá las instituciones artísticas se hiciesen más permeables, de este modo, a una mayor diversidad de perspectivas (entre otras, la feminista) y los departamentos museísticos que se muestran más abiertos a la sociedad y más proclives a aceptar propuestas desde abajo (como suelen ser, por ejemplo, los educación o de actividades públicas) podrían influir con más fuerza en las decisiones que se toman en el "núcleo duro" del museo ${ }^{4}$.

${ }^{3}$ Ver http://www.museoreinasofia.es/visita/tipos-visita/visita-autonoma/feminismo

${ }^{4}$ Un ejemplo en este sentido lo encontramos en el Museu d' Art Contemporani de Barcelona (MACBA). El departamento de actividades públicas del museo hizo, en la primera mitad de la década de 2000, un esfuerzo muy meritorio por explorar los puntos de confluencia entre el pensamiento feminista (y en particular, la teoría queer), el activismo y la cultura visual en una serie de encuentros y seminarios: entre otros, habría que citar el seminario Maratón Posporno. Pornografía, pospornografía: estéticas y políticas de la representación sexual (dirigido por Beatriz Preciado en junio de 2003); las dos ediciones del seminario- taller Tecnologías del género. Identidades minoritarias y sus representaciones críticas (2004 y 2005); o la incorporación de un módulo sobre "Tecnologías del género" en el plan de estudios del Programa de Estudios Independientes (PEI), iniciado por el Museo en 2006. Como tuve ocasión de explicar en más detalle en el catálogo de la exposición Genealogías feministas (MAYAYO, 2012: 2931), el esfuerzo realizado por incorporar el legado feminista en la programación de actividades públicas del MACBA no se ha visto reflejado, en igual medida, en la política expositiva del museo.

Lo mismo podríamos decir del Museo Nacional Centro de Arte Reina Sofía. Su departamento de actividades públicas ha mostrado un interés constante, en los últimos años, por las políticas feministas y queer: recordemos, por citar tan solo los casos más recientes, el curso Somateca. Vivir y resistir en la condición neoliberal, coordinado por Beatriz Preciado en 2012 y 2013; el seminario En torno a 
En noviembre de 2012, con ocasión de la celebración de las mesas de trabajo "Horizontes del arte en España", organizadas por el MNCARS, la Fundación Banco de Santander e YGBART, tuve ocasión de participar en el grupo "Grandes narraciones del arte español en los museos y colecciones públicas". Creo que algunas de las conclusiones que publicamos entonces siguen siendo válidas hoy día: "[es necesario] impulsar cambios en el modelo de los organigramas de los museos, regidos en general por una lógica patriarcal y personalista. Frente a modelos de organización piramidales basados en férreas jerarquías, el museo tendría que adoptar modos de organización más horizontales y participativos -señalábamos. El cambio en los modos de narrar debe ir acompañado de un cambio en la cultura de trabajo y en las formas de organización de las instituciones". Y añadíamos: "sería deseable potenciar la participación de los públicos o las audiencias en la vida del museo. Para lograrlo, sugerimos las siguientes líneas de trabajo: impulsar la labor de los departamentos de educación, hacer que los programas educativos estén presentes en el diseño de exposiciones desde el inicio (y no como punto final de un proyecto), mejorar las condiciones de trabajo de los educadores, articular formas de diálogo e intercambio con los distintos públicos o comunidades de interés locales" ( Informe de la mesa "Grandes narraciones del arte español en los museos y colecciones públicas"”, 2012).

\section{LAS "POLÍTICAS DE SABER FEMINISTAS" EN LOS MUSEOS}

Un aspecto importante, en este sentido, es la introducción de lo que Laura TrafíPrats, siguiendo a Hilde Hein, denomina las "políticas de saber feministas en el museo". Como apunta la autora, "una de las estrategias del feminismo es construir conocimiento desde la experiencia compartida, crear espacios de encuentro y conversación, implicarse y responder a las historias de los objetos, en definitiva construir lugares para la relacionalidad horizontales que parten del reconocimiento del otro" (Trafí-Prats, 2010: 227). Así, esta incorporación de los saberes feministas en los centros de arte no siempre ha de traducirse necesariamente en la organización de actividades de "temática feminista", sino que puede servir para activar proyectos que pongan en el centro el "estar en relación", que propicien espacios de intercambio y co-aprendizaje entre públicos no siempre interesados a priori en las teorías feministas y queer. Del mismo modo, muchos de estos proyectos "utilizan la institución como apoyo, pero fundamentalmente ocurren fuera de la misma planeando redes y relaciones con el saber alternativas, pero al mismo tiempo ofreciendo espacios de

Genealogías feministas en el arte español, 1960-2010, organizado junto al MUSAC en febrero de 2013; el ciclo audiovisual El silencio del palacio. Perspectivas del cine feminista (marzo 2012) o el ciclo La internacional cuir. Transfeminismo, micropolíticas sexuales y vídeo-guerrilla (noviembre de 2011). Tampoco aquí, como analizamos en este artículo, esta actividad se ha visto reflejada en la política expositiva y, sobre todo, en la colección permanente del museo. 
trabajos y producción cultural del género desde la subcultura y la subalternidad" (trafí-Prats, 2010: 227).

Un ejemplo destacable es el proyecto Hipatia, colaboración del Departamento de Educación y Acción Cultural (DEAC) del MUSAC con el centro penitenciario de León, que entre 2007 y 2001 ha dado lugar a la publicación de una revista de textos e imágenes producidos por mujeres recluidas en el módulo 10 de este centro y elaboradas a partir de encuentros semanales con miembros del DEAC. En palabras de Trafí-Prats:

"Hipatia posibilita espacios de expresión, toma de voz y agenciamiento individual a través de la escritura de textos de experiencias personales, solidaridad con otros grupos de mujeres, acontecimientos que suceden en el mundo, conocimiento de mujeres escritoras, activistas, escritura de ficción, etc. Pero también representa producciones visuales y textuales que reflexionan sobre la experiencia colectiva de las mujeres en la cárcel, definidas por temas que permiten pensarse en relación; cuestiones como la sexualidad, la raza, las normas sociales, el cuidado, la salud. Algunos de los discursos expresivo-creativos que aparecen en la revista son motivados por un diálogo con alguna obra expuesta en un momento determinado en el MUSAC, otros son el producto de trabajos directos con artistas que visitan la cárcel como María Galindo, de Mujeres Creando, o Virginia Villaplana, quien realiza un ejercicio de lectura-escritura basado en su libro de poemas Zonas de intensidades" (Trafí-Prats, 2010: 228).

Otro ejemplo, aparentemente más alejado del feminismo, es la creación del grupo de investigación "Península. Procesos coloniales y prácticas artísticas y curatoriales". Amparado por el Centro de Estudios del MNCARS, pero al mismo tiempo autónomo con respecto a la institución, Península se define como "una plataforma de debate sobre arte, colonialidad y curaduría en relación a la historia de España y Portugal, sus procesos coloniales y la latencia de sus relaciones de poder en el presente. El grupo propone a investigadores, académicos, estudiantes de posgrado, artistas e interesados en este tema de debate la participación en una serie de encuentros de trabajo y discusión"5. Así, el papel del MNCARS consiste aquí en proporcionar una infraestructura y un lugar de reunión al grupo, pero sobre todo en servir de nexo de unión entre una serie de investigadores y personas interesadas que, por su dispersión y aislamiento, difícilmente hubieran podido entrar en contacto de no ser por la mediación ejercida por el museo. La función de éste es, siguiendo la descripción de Trafí-Prats, la de propiciar un espacio de encuentro, la de activar relaciones: relaciones entre investigadores, pero también relaciones entre éstos y la propia

\footnotetext{
${ }^{5}$ Ver http://www.museoreinasofia.es/pedagogias/centro-estudios/grupos-investigacion/peninsula
} 
institución. Un aspecto este último que no se halla exento de conflicto: ¿No podría pensarse, en efecto, que la institución intenta fagocitar, en su propio beneficio, el trabajo realizado por esta red (en teoría) independiente? ¿Hasta qué punto condiciona el marco institucional el trabajo que se realiza en la plataforma de investigación? ¿Se puede mantener realmente la autonomía desde dentro? Y al contrario, ¿no podríamos pensar que el encuentro entre este tipo de grupos independientes (o semiindependientes) y el museo pueda terminar propiciando ciertos cambios o innovaciones en los discursos museísticos? ¿Que pueda "contaminar", como decíamos antes, al resto de la institución?

Si queremos que esto ocurra, debemos reflexionar sobre las estrategias más adecuadas para fomentar esa "contaminación". En el caso concreto de los saberes feministas, habría que plantearse si resulta más eficaz intentar conquistar espacios concretos dentro del museo (exposiciones ad hoc, salas específicas dentro de la colección, seminarios especializados, etc. ) o buscar que las perspectivas feministas estén presentes, de forma transversal, en todos los discursos y espacios de la institución. La pregunta, desde luego, no es nueva y lleva modulándose, en distintos registros, desde los años sesenta del siglo pasado: ¿Hay que impulsar exposiciones de mujeres o, por el contrario, lograr una cuota igualitaria de participación femenina en exposiciones mixtas? ¿Es mejor diseñar cursos o seminarios especializados sobre la historia de las mujeres artistas o las prácticas artísticas feministas o intentar que estos contenidos estén presentes en todas las asignaturas de los planes de estudio de ciertas carreras universitarias? ¿Debemos crear, en las colecciones permanentes de los museos, salas o itinerarios concretos reservados a la producción de las mujeres o integrarla dentro del conjunto del recorrido expositivo?

Existen, en mi opinión, argumentos sólidos para defender ambas posturas. Por una parte, cabría pensar que dado que tanto la aportación de las mujeres como las luchas feministas han sido invisibilizadas a lo largo de la historia en los discursos dominantes, es necesario destacar su presencia creando espacios y proyectos específicos que se dediquen, en exclusiva, a estudiar el legado de las mujeres artistas y/o de las prácticas feministas. Incorporar este legado como elemento transversal en discursos o eventos de carácter más global podría diluir, a ojos de los receptores y receptoras (sea el público de una exposición, las/os asistentes a un congreso científico o el estudiantado universitario), la fuerza e importancia de las aportaciones de las mujeres y de las perspectivas feministas, así como transmitir una imagen de "normalidad" allí donde en realidad no ha existido sino constante discriminación. Crear "una habitación propia" para los discursos feministas y las obras de las mujeres artistas es una forma de hacer especial énfasis en aquello que ha sido borrado en el pasado, pero también de poner de relieve los propios procesos ideológicos que han dado lugar a esa obliteración. 
Por otra parte, sin embargo, podríamos argumentar que la verdadera fuerza de la herencia política e intelectual del feminismo no radica (o no solo, al menos) en la incorporación de unos "temas" o de unas obras, sino en su capacidad de propiciar nuevas formas de narrar y nuevos modos de conocimiento. De poco nos sirve, por ejemplo, introducir una o varias salas consagradas a mujeres artistas o a prácticas feministas en la colección permanente de un museo si ello no sirve para desestabilizar la estructura narrativa del museo en su conjunto, si no logramos resquebrajar las bases patriarcales (sexistas, clasistas, racistas...) en las que se asienta la historia del arte. Más aún, reservar una sala a las mujeres artistas en un centro de arte o dedicar un curso a las prácticas feministas en el currículo académico puede servir de coartada ideológica a las instituciones artísticas o educativas para no hacer cambios más profundos: se cumple con las apariencias y se desactivan los aspectos más subversivos o revolucionarios del feminismo, aspectos que necesariamente supondrían poner patas arriba la institución en su totalidad.

Un ejemplo de este proceder lo hallamos en la reciente reorganización de la tercera parte de la colección permanente del Museo Reina Sofía, "De la revuelta a la posmodernidad (1962-1982)". Según puede leerse en la página web del museo, esta sección aborda "los cambios políticos, sociales, culturales y tecnológicos que configuran el escenario global contemporáneo: la descolonización, las revueltas del 68, los movimientos feministas, la crisis económica, la expansión de la cultura

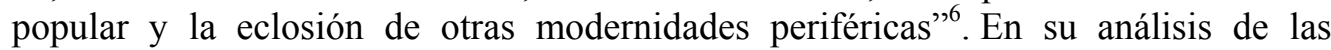
prácticas feministas, los/as responsables del diseño de la colección parecen haberse inclinado por el enfoque monográfico frente al transversal, ya que dedican la sala 7 del recorrido a "La revolución feminista". Lo criticable, a mi entender, no es la decisión adoptada, sino que una vez asumida esta opción se lleve a cabo con escasa convicción. En efecto, la sala 7 es un espacio de transición, cuyo escasísimo tamaño contrasta con la amplitud del resto de las estancias. Mientras que en otros puntos del recorrido se ha optado por separar el análisis de la escena internacional del estudio del arte español (hay salas dedicadas específicamente al estudio del arte experimental en España o incluso espacios consagrados, de forma monográfica, a una sola obra, como la instalación Tropicália de Helio Oiticica o Soledad interrumpida de José Luis Alexanco y Luis de Pablo), en la sala 7 se apiñan obras de artistas españolas y extranjeras a la vez (Esther Ferrer, Ángels Ribé, Paz Muro, Concha Jérez o Eugènia Balcells, junto a Hackney Flashers Collective, Martha Rosler o Liliana Porter). En la selección de piezas parece producirse una cierta confusión entre las categorías "mujer artista" y "práctica feminista": ¿Cómo entender la inclusión de proyectos como Arruga Instalación ambiente I, de Porter, en un espacio titulado "la revolución feminista"? ¿Y por qué se han relegado, en cambio, a los almacenes obras

${ }^{6}$ Ver http://www.museoreinasofia.es/coleccion/coleccion-3 
emblemáticas de la práctica feminista en nuestro país como La discriminació de la dona (1977) de Eulàlia Grau o Influencia cultural, y nada más que cultural, de la mujer en las artes arquitectónicas, visuales y otras (1975) de Paz Muro? Si realmente la eclosión de la segunda ola feminista supuso una "revolución", como indica el título elegido para la sala, ¿por qué otorgarle un espacio tan reducido? ¿Por qué convertirlo en una especie de totum revolutum? ¿No será que la inclusión de la "salita feminista" sirve de coartada para despachar rápidamente el asunto sin que incida, en realidad, en la orientación de la colección?

\section{MODELOS HISTORIOGRÁFICOS PROPIOS.}

Reorientar nuestras estrategias supone también cuestionar nuestros modelos historiográficos. Éste es un aspecto que centró buena parte de nuestras preocupaciones al concebir la exposición Genealogías feministas. Como tuve ocasión de señalar en el catálogo de la muestra, las categorías acuñadas en la historiografía feminista anglosajona no siempre resultan útiles a la hora de analizar el contexto español (Mayayo, 2012: 32 y ss). Por ejemplo, puede que la etiqueta "Feminist Art" ("arte feminista") sea adecuada para describir la escena angloamericana en los años setenta, pero es mucho más dudoso que lo sea para estudiar nuestra historia. En primer lugar, a diferencia de lo que ocurrió en Estados Unidos o Gran Bretaña, en la España de los setenta las artistas se mostraron muy reacias a identificarse como "feministas". La persistencia soterrada de modelos de conducta heredados del nacional-catolicismo, la estigmatización del término "feminista" en una sociedad tan machista como era la del tardofranquismo (también imperaba el machismo, no lo olvidemos, en los ambientes antifranquistas) y la prioridad que tenía en España la lucha contra la dictadura frente a cualquier otro tipo de reivindicación política hicieron que muchas artistas manifestasen reticencias con respecto al movimiento de mujeres.

En segundo lugar, hay que tener en cuenta que, mientras en el ámbito anglosajón las artistas feministas han tendido a mirarse en el espejo de las generaciones anteriores (ya fuese para identificarse con ellas o para cuestionarlas), en España la historia de las relaciones entre la práctica artística y las políticas feministas ha estado marcada por frecuentes discontinuidades y rupturas. Como señalaron en su día Carmen Navarrete, María Ruido y Fefa Vila, es en la década de los noventa cuando el mundo artístico español empieza a mostrarse más permeable a la influencia de los discursos feministas (Navarrete, Ruido y Vila, 2005). En torno a 1992 se celebran las primeras individuales de Marina Nuñez, Carmen Navarrete, Eulàlia Valldosera y otras artistas feministas destacadas; por la misma época, se fundan colectivos artísticos inspirados por el activismo feminista y queer como LSD en Madrid o Erreakzioa-Reacción en Euskadi. Sin embargo, lo curioso es que este grupo de 
artistas feministas parezca haber surgido, en cierto modo, de la nada. ¿Dónde están sus predecesoras? ¿Cuáles son sus puntos de referencia, sus modelos? En mayo de 2005, la revista ExitExpress publicaba un dossier monográfico titulado "Mujeres, arte y feminismo", en el que se incluía una encuesta realizada a varias creadoras españolas. Una de las preguntas planteadas era: “¿Cuál ha sido la repercusión [en su obra] de las artistas feministas de los setenta?" Si bien la mayor parte de las encuestadas reconocía la deuda que tenían con el legado de los setenta, todas citaban invariablemente a artistas extranjeras (Annette Messager, Barbara Kruger, Marina Abramovic, Martha Rosler, Ana Mendieta, etc.) cuando se les preguntaba acerca de sus referentes históricos (Dossier "Mujeres, arte y feminismo", 2005).

Dicho de otro modo, a diferencia de lo ocurrido en el contexto anglosajón, en España muchas artistas y críticas feministas nacidas después de los años sesenta crecieron huérfanas de modelos propios, con la mirada puesta en textos y debates importados de fuera. En sus testimonios se percibe un mismo síndrome de tabula rasa, un mismo cansancio por la sensación de estar siempre empezando desde cero: "A mí me parece mal que durante mi etapa de formación no haya tenido posibilidad de tener contacto con el trabajo de otras mujeres artistas dentro de un contexto más cercano y que haya tenido que crecer con la idea de que eso no existían y tener que tirar de otras historias, de otras genealogías diferentes"-declara, por ejemplo, Carmen Navarrete. Creo que es importante y necesario encontrar una historiografía cercana a nosotras, que pueda servir de genealogía de las cosas que podemos hacer a la gente que trabajamos en el mundo del arte, y también si trabajamos en otros ámbitos" ("Debate II", 2008: 246).

De ahí la importancia que concedíamos en la exposición Genealogías feministas a la tarea de construir genealogías propias. De ahí también la necesidad, antes comentada, de encontrar herramientas historiográficas que sirvan para analizar las singularidades del caso español, sin intentar encajarlo artificiosamente en unos esquemas importados. Estas singularidades no solo afectan a la forma en la que ha ido evolucionando la práctica artística, sino también al modo en que ha ido constituyéndose la propia historiografía feminista. Aunque la realidad es siempre más compleja, en el mundo anglosajón podría decirse que los debates historiográficos han seguido una evolución bastante lineal. Mientras que en los años setenta se hizo hincapié sobre todo en rescatar del olvido la obra de las mujeres artistas del pasado, en un segundo momento se señalaron las limitaciones de dicho enfoque: hacer historia de las mujeres -observaron algunas voces- no era suficiente si no se renovaban al mismo tiempo las herramientas historiográficas; además, era necesario distinguir entre el arte producido por mujeres y la práctica feminista, sentando así las bases de una politización de la disciplina de la historia del arte. En un tercer momento, el panorama va cambiando: nos encontramos, por un lado, con una serie de textos y exposiciones que cuestionan el "canon oficial" del arte feminista que se había 
ido estableciendo en décadas anteriores e intentan superar el enfoque excesivamente anglocéntrico de sus predecesoras, subrayando el carácter internacional de los movimientos feministas; por otra, desde posiciones próximas a la teoría queer, se empieza a cuestionar con fuerza la primacía del sujeto "mujer" como sujeto político central de la lucha feminista, abogando por una desestabilización de las categorías identitarias (entre otras, las categorías "mujer artista" o "artista feminista").

Este esquema evolutivo no puede aplicarse en modo alguno al caso español. No solo porque la penetración de los discursos feministas en la historia del arte en nuestro país ha sido más tardía (aunque en los años ochenta pueden destacarse las aportaciones de autoras/es pioneras/as como Estrella de Diego o Juan Vicente Aliaga, no existe un corpus significativo de textos hasta finales de la década siguiente), sino también porque todas las fases descritas anteriormente se han dado aquí al mismo tiempo y de forma "desordenada" (si entendemos por "orden" la referencia anglosajona). El mismo carácter tardío que ha tenido la aceptación de las perspectivas feministas en la disciplina de la historia del arte ha hecho que, por ejemplo, la recepción de la teoría queer se haya dado antes, en ocasiones, que la de modelos supuestamente más "antiguos" como la historia de las mujeres artistas; o que hayan convivido al mismo tiempo en las salas de los museos españoles exposiciones sobre mujeres artistas, prácticas feministas y movimientos transfeministas; o que la obra de las artistas más jóvenes haya sido, muchas veces, más vista y estudiada que la de la de las "pioneras" de los setenta, que han tenido que esperar a la segunda mitad de la década de 2000 para que su papel empiece a ser reconocido como se merece.

Por estas razones, las tareas que tenemos pendientes son muchas, variadas e incluso pueda parecer que contradictorias. En mi opinión, es necesario seguir trabajando en todos estos frentes a la vez: en el descentramiento del sujeto "mujer", pero también en el estudio del legado de las mujeres artistas; en el terreno de una práctica feminista expandida y en el campo de la historia de las mujeres; en el estudio de las fuentes primarias y en la reflexión teórica. A las voces que señalan que la historia de las mujeres artistas es un asunto "superado", se podría responder que difícilmente puede estar superado aquello que apenas se ha iniciado. En efecto, llama la atención el escaso número de investigaciones en este campo de las que disponemos todavía en España: los trabajos de Pilar Muñoz López y otras estudiosas deben ser completado con nuevos estudios, nuevas tesis doctorales, nuevos artículos en revistas especializadas (Muñoz López, 2004). Algunas dirán que ya es tarde para emprender lo que en otros países se hizo hace treinta años. Pero esta afirmación solo puede suscribirse si se asume el modelo de modernidad de cuño anglosajón como el único posible. ¿Por qué no pensar que estos "desfases" frente al modelo normativo conllevan también ciertas ventajas? Con el bagaje que tenemos ahora, resulta mucho más fácil escapar a la ingenuidad que destilaban, a veces, los primeros textos de las historiadoras feministas anglosajonas e incorporar al estudio del arte español toda esa 
riqueza de debates ideológicos e historiográficos de las que nos hemos ido nutriendo en las últimas décadas.

\section{BIBLIOGRAFÍA}

ALIAGA, J. V. y MAYAYO, P. (eds.) (2012): Genealogías feministas en el arte español, 1960-2010. Madrid: MUSAC/This Side Up.

FERNÁNDEZ LÓPEZ, O. (2012): El feminismo en los discursos expositivos y relatos museográficos desde los años noventa. En Aliaga, J.V. y Mayayo, P., eds., Genealogías feministas en el arte español, 1960-2010, 95-118. Madrid: MUSAC/This Side Up.

Debate II: Jesús Martínez Oliva, Carmen Navarrete, Chelo Matesanz, Assumpta Bassas (2008). En Aliaga, J.V., ed., A voz e a palabra. Coloquio sobre A batalla dos xéneros, 238-254. Santiago de Compostela: Xunta de Galicia.

"Dossier Mujeres, arte y feminismo". EXITExpress, nº 12, mayo de 2005.

Informe $M A V n^{\circ} 10$, enero de 2013, en http://www.mav.org

Informe de la mesa de trabajo "Grandes narraciones del arte español en los museos y colecciones públicas"'", noviembre de 2012, Proyecto Horizontes del arte en España, en http://www.blogfundacionbancosantander.com/horizontes/

MAYAYO, P. (2012): Imaginando nuevas genealogías. Una mirada feminista a la historiografía del arte español. En Aliaga, J.V. y Mayayo, P., eds., Genealogías feministas en el arte español, 1960-2010, 19-38. Madrid: MUSAC/This Side Up.

MUÑOZ LÓPEZ, P. (2004): Mujeres españolas en las artes plásticas. Madrid: Síntesis.

NAVARRETE, C., RUIDO, M. y VILA, F. (2005): Trastornos para devenir: entre artes y políticas feministas y queer en el Estado español. En Desacuerdos. Sobre arte, políticas y esfera pública en el Estado español, Vol. 2, 158-187. San Sebastián, Barcelona y Sevilla: Arteleku/MACBA/Universidad Internacional de AndalucíaUNIA arte y pensamiento.

TRAFÍ-PRATS, L. (2010): De la cultura feminista en la institución arte. En Desacuerdos. Sobre arte, políticas y esfera pública en el Estado español, Vol. 7, 214245. Desacuerdos. Sobre arte, políticas y esfera pública en el Estado español, Vol. 7. Granada, Barcelona, Madrid y Sevilla: Centro José Guerrero-Diputación de Granada/MACBA/MNCARS/Universidad Internacional de Andalucía-UNIA arte y pensamiento. 